\title{
Kinetic Investigation of Catalytic Disproportionation of Superoxide Ions in the Non- aqueous Electrolyte used in Li-Air Batteries
}

Qiang Wang ${ }^{1}$, Dong Zheng ${ }^{1}$, Meaghan E. McKinnon ${ }^{1}$ Xiao-Qing Yang ${ }^{2}$ and Deyang Qu ${ }^{* 1}$

1, Department of chemistry, University of Massachusetts Boston, 100 Morrissey Blvd., Boston, MA 02125 USA

2, Chemistry Department, Brookhaven National Laboratory, Upton, NY, 11973, USA

22

\begin{abstract}
Super $_{0}$ xide reacts with carbonate solvents in Li-air batteries. Tris(pentafluorophenyl)borane is found to catalyse a more rapid superoxide $\left(\mathrm{O}_{2}{ }^{-}\right)$disproportionation reaction than the reaction between superoxide and propylene carbonate (PC). With this catalysis, the negative impact of the reaction between the electrolyte and $\mathrm{O}_{2}{ }^{-}$produced by the $\mathrm{O}_{2}$ reduction can be minimized. A simple kinetic study using ESR spectroscopy was reported to determine reaction orders and rate constants for the reaction between PC and superoxide, and the disproportionation of superoxide catalyzed by Tris(pentafluorophenyl)borane and $\mathrm{Li}$ ions. The reactions are found to be first order and the rate constants are $0.033 \mathrm{~s}^{-1} \mathrm{M}^{-1}, 0.020 \mathrm{~s}^{-1} \mathrm{M}^{-1}$ and $0.67 \mathrm{~s}^{-1} \mathrm{M}^{-1}$ for reactions with PC, Li ion and Tris(pentafluorophenyl)borane, respectively.
\end{abstract}

Keywords: superoxide disproportionation; Lewis Acid Catalyst; Li-air battery; reaction rate constant.

\section{Introduction:}

Li- $\mathrm{O}_{2}$ battery chemistry has aroused significant interests due to its high theoretical specific capacity, which far exceeds state-of-art Li-ion batteries, due to the cathode active material $\left(\mathrm{O}_{2}\right)$ being abundant in the air. However, before Li-air chemistry becomes applicable, there are many

* Corresponding author: Tel: +1 617287 6035; Fax: +1 617287 6185: e-mail: deyang.qu@umb.edu 
technical obstacles that need to be addressed. Among them is the chemical reaction between the superoxide $\left(\mathrm{O}_{2}{ }^{-}\right)$and many carbonate solvents e.g. propylene carbonate (PC). $\mathrm{O}_{2}{ }^{-{ }^{-}}$has been identified as the product of 1-e $\mathrm{O}_{2}$ reduction in non-aqueous electrolytes [1-3]. $\mathrm{O}_{2}{ }^{--}$can react with organic solvents and specially carbonate solvents. The reaction will not only consume the electrolyte but also form undesired non-rechargeable products e.g. $\mathrm{Li}_{2} \mathrm{CO}_{3}$ [4,5]. Efforts have been made to search for the solvents which resist to react with $\mathrm{O}_{2}{ }^{-}[6,7]$. We believe that the chemical interaction between the superoxide ions and the electrolyte is one of a few competing parallel reactions that $\mathrm{O}_{2}{ }^{--}$may undergo, the disproportionation $\mathrm{O}_{2}{ }^{-{ }^{-}}$would be another possible reaction. To alleviate the problems associated with the $\mathrm{O}_{2}{ }^{-}$/electrolyte reactions, we have attempted to facilitate the rapid disproportionation, while hindering its chemical interaction with the electrolyte. Peroxide ions $\left(\mathrm{O}_{2}{ }^{2-}\right)$ act as a Lewis base and can be stabilized by strong Lewis acid. When a strong Lewis acid-base complex is formed, $\mathrm{O}_{2}{ }^{--}$could be driven to disproportionate to $\mathrm{O}_{2}$ and encapsulated $\mathrm{O}_{2}{ }^{2-}$. Tris(pentafluorophenyl) borane (TPFPB) is a strong boron-based Lewis acid. Indeed, we discovered that TPFPB can catalyze rapid disproportionation of $\mathrm{O}_{2}{ }^{-}$. Such catalytic disproportionation of $\mathrm{O}_{2}{ }^{--}$is much faster than its chemical reaction with aprotic electrolyte [8], so the $\mathrm{O}_{2}{ }^{-}$ions become disproportionated before reacting with the solvents. Therefore the issues associated with the chemical interaction between $\mathrm{O}_{2}{ }^{--}$and the electrolyte can be alleviated. In this paper, we reported the quantitative determination of the reaction rate constants for the catalytic disproportionation.

\section{Experimental details}

All reagents were purchased from Sigma-Aldrich except tris(pentafluorophenyl) borane (TPFPB) which was synthesized in-house at Brookhaven National Laboratory according to the procedures reported in the literature [9]. Anhydrous grade propylene carbonate (PC) and dimethyl sulfoxide (DMSO) were further dried in-house using $5 \AA$ molecule sieves, which were vacuum dried at $400{ }^{\circ} \mathrm{C}$ before use. The moisture in PC and DMSO was less than $20 \mathrm{ppm}$ as measured by Karl Fisher titration. The purity of 1.1-diphenyl-2-picrylhydrazyl (DPPH) was determined by UV visible spectroscopy as its absorptivity at $520 \mathrm{~nm}$ in ethanol is $12350 \mathrm{lM}^{-1} \mathrm{~cm}^{-1}[10,11]$. The purity was found to be $93.8 \%$.

Electron Spin Resonance (ESR) measurements were conducted using an ESR spectrometer model CMS8400 made by Resonance Instrument, Inc. 
A standard for a quantitative ESR measurement is a stable material with a known number of spins that has similar line shape and width. Pure paramagnetic compounds with known spin concentrations are normally used as primary standards. $\mathrm{MnO}_{2}$ diluted in $\mathrm{MgO}(\mathrm{S}=5 / 2)$ and DPPH (free radical, $S=1 / 2$ ) were proven as reliable primary standard for quantitative ESR spectroscopy [11]. DPPH was chosen in our experiments as ESR standard. DPPH is the oldest and most commonly used ESR standard. Its g-value is 2.0037 \pm 0.0002 and is independent from the solvent. DPPH also has the same spin quantum number as $\mathrm{O}_{2}{ }^{--}$. Five samples with gradually increased concentrations were prepared by dissolving the carefully weighed DPPH in DMSO solvent. $280 \mu \mathrm{l}$ of the standard solutions were transferred into ESR sample tubes (outer diameter $4 \mathrm{~mm}$ ). The sample tube was then placed carefully into the cavity of ESR instrument so that it was vertically and horizontally centered in the cavity, which is critical for accurate measurements [12-14].

The kinetic experiments were conducted by injecting the catalysts (TPFPB and Li salt) or reactant (PC) into $\mathrm{KO}_{2}$ DMSO solution. The decrease of $\mathrm{O}_{2}{ }^{--}$concentration was monitored by ESR at $-50^{\circ} \mathrm{C}$. Catalytic disproportionation of $\mathrm{O}_{2}{ }^{-{ }^{-}}$is a very fast reaction [8]. In order to acquire an adequate amount of data points, low $\mathrm{O}_{2}{ }^{--}$concentration and a small amount of TPFPB were used. 0.15M 18-crown-6 DMSO solution was used to assist the dissolution of $\mathrm{KO}_{2}$. During the kinetic experiments, a small amount of reactant or catalyst was injected in $280 \mu \mathrm{l}$ of $0.0108 \mathrm{M}$ of $\mathrm{KO}_{2}$ DMSO solution. After certain duration at $22^{\circ} \mathrm{C}$, the sample tube was put in the ESR cavity kept at $-50^{\circ} \mathrm{C}$, at which temperature ESR measurements were taken. At $-50^{\circ} \mathrm{C}$, both the chemical reaction and disproportionation ceased, while the intensity of $\mathrm{O}_{2}{ }^{.-}$signal remained constant at the temperature. The sample tube was then taken out of the cavity and warmed up to $22^{\circ} \mathrm{C}$ in a water bath allowing the reaction to proceed periodically. It took about 15 seconds to warm up the sample to $22^{\circ} \mathrm{C}$.

\section{$3 \quad$ Results and Discussion}

Electron Spin Resonance (ESR), also known as electron paramagnetic resonance (EPR), is a unique technique for the investigation of species containing unpaired electrons like the superoxide ion, $\mathrm{O}_{2}{ }^{--}$. The concentration of the species can be determined by measuring the spin concentration, since the spin number is proportional to the amount of species. One of the most difficult tasks in ESR is the quantitative ESR measurement of the spin number. The most 
practical and reliable way to determine the spin concentration is to compare the integrated area of the sample spectrum with that of an appropriate standard, as the method of absolute spin concentration estimation is difficult and even impossible in some cases. In the current investigation, DPPH was used as standard since both $\mathrm{O}_{2}{ }^{-}$and $\mathrm{DPPH}$ are free radicals, $\mathrm{S}$ is $1 / 2$. It has been reported that DPPH will remain stable in the solution at room temperature with its ESR signal unchanged for many days [12]. The spin concentration of the superoxide and the standard was determined from the double integration of the ESR peak. Assuming the Curie law was followed, the ratio of the number of spins or spin concentration $(\mathrm{spin} / \mathrm{cm})$ of $\mathrm{O}_{2}{ }^{--}$and DPPH can be expressed as [12]:15

$$
\frac{N_{O_{2}^{-}}}{N_{D P P H}}=\frac{g_{O_{2}^{-}}}{g_{D P P H}} \frac{S_{O_{2}^{-}}\left(S_{O_{2}^{-}}+1\right) A_{O_{2}^{-}}}{S_{D P P H}\left(S_{D P P H}+1\right) A_{D P P H}}
$$

Where $A$ is the double integrated area, $g$ is the average $g$ value and $S\left(S=1 / 2\right.$ for both $\mathrm{O}_{2}{ }^{-{ }^{-}}$and $\mathrm{DPPH})$ is the spin. The average $g$ values for the $\mathrm{O}_{2}{ }^{--}$and DPPH are both around 2.0023.

A standardization curve was first generated using DPPH DMSO solutions with known concentration. The standardization curve is shown in Figure 1. A clear linear relationship is demonstrated for quantitative analysis. Therefore, the concentration of $\mathrm{O}_{2}{ }^{--}$can be determined from the double integration of the ESR peak.

figure 1

Non-catalyzed disproportionation of $\mathrm{O}_{2}{ }^{--}$has greater enthalpies than the difference between singlet state and triplet state of $\mathrm{O}_{2}$; therefore, $\mathrm{O}_{2}{ }^{--}$is relatively stable in aprotic solvents e.g. DMSO. The stability of $\mathrm{O}_{2}{ }^{--}$in DMSO solution was demonstrated in our previous publication [8], where there were no apparent changes of $\mathrm{O}_{2}^{--}$ion after 12 hours storage at room temperature. However, if there exists a Lewis acid, even as $\mathrm{Li}^{+}$, the disproportionation of $\mathrm{O}_{2}{ }^{-}$ becomes thermodynamically favorable [14]

$$
\begin{gathered}
\mathrm{O}_{2}^{--}+\mathrm{Li}^{+} \rightarrow \mathrm{LiO}_{2} \\
2 \mathrm{LiO}_{2}+\mathrm{O}_{2}^{-} \rightarrow \mathrm{Li}_{2} \mathrm{O}_{2}+2 \mathrm{O}_{2} \uparrow \\
2 \mathrm{LiO}_{2} \rightarrow \mathrm{Li}_{2} \mathrm{O}_{2}+\mathrm{O}_{2} \uparrow
\end{gathered}
$$


In a Li-air battery, $\mathrm{Li}$ salts are normally used in the electrolyte; therefore the catalytic disproportionation by $\mathrm{Li}$ ion was of interest to be investigated. Figure 2 shows the ESR spectra taken at the different times for the solution of $0.01 \mathrm{M} \mathrm{KO}_{2}$ DMSO with $0.2 \mathrm{M}$ of $\mathrm{LiBF}_{4}$ added. It is clearly evident that $\mathrm{O}_{2}{ }^{--}$was consumed by the disproportionation catalyzed by $\mathrm{Li}$ ions in the electrolyte.

figue2

$\mathrm{O}_{2}{ }^{--}$ion is a powerful nucleophile in aprotic solvents. In particular, it subjects PC to a ringopening attack that produces a variety of organic salts. As reported in ref 8, PC is not oxidized by $\mathrm{O}_{2}{ }^{--}$in the electrolyte at rate competitive with $\mathrm{O}_{2}{ }^{--}$disproportionation catalyzed by TPFPB. Therefore the irreversible consumption of PC solvent by the $\mathrm{O}_{2}$ reduction product, $\mathrm{O}_{2}{ }^{-}$, could be minimized with the addition of TPFPB catalyst. The reaction rate constants were determined by ESR spectroscopy. $0.08 \mathrm{M}$ of PC, $0.2 \mathrm{M}$ of $\mathrm{LiBF}_{4}$ and $0.009 \mathrm{M}$ of TPFPB were added in three $280 \mu \mathrm{l}$ of $0.01 \mathrm{M} \mathrm{O}_{2}{ }^{--}$DMSO solution. It is worth mentioning that different concentrations of PC, $\mathrm{Li}^{+}$and TPFPB were added into the DMSO solution with the same concentration of $\mathrm{O}_{2}{ }^{-{ }^{-}}(0.01$ $\mathrm{M})$ in order to achieve the reaction rate that an adequate amount of data points can be acquired. The decrease of $\mathrm{O}_{2}{ }^{-}$ions was determined using ESR spectroscopy. The reaction order and rate constants were therefore determined. Figure 3 shows the change of natural logarithm of $\mathrm{O}_{2}{ }^{--}$ concentration with time. A nice linear relationship was demonstrated for all three reactions. Thus, all three reactions are first order against $\mathrm{O}_{2}{ }^{--}$. The rate equation for the chemical reaction involving superoxide is given by:

$$
\frac{d\left[\mathrm{O}_{2}^{-}\right]}{d t}=k[\text { Reactant }]\left[\mathrm{O}_{2}^{-}\right]^{n}
$$

[Reactant] represents PC, $\mathrm{Li}^{+}$and TPFPB concentration. Since the concentration of reactant (PC) and catalyst (TPFPB) remain constant, then,

$$
k^{\prime}=k[\text { Reactant }]
$$

The rate equation will be:

$$
\frac{d\left[O_{2}^{-}\right]}{d t}=k^{\prime}\left[O_{2}^{-}\right]^{n}
$$


$k^{\prime}$ is now an apparent rate constant and $n$ is the reaction order.

For a first order reaction, $n=1$, the integration for the rate equation yields:

$$
\ln \left[O_{2}^{-}\right]=-k^{\prime} t+\ln \left[O_{2}^{-}\right]_{o}
$$

Where $\left[\mathrm{O}_{2}{ }^{--}\right]$is the initial concentration of superoxide. Therefore, if the $\ln C$ plot with $\mathrm{t}$, a straight line should be demonstrated, the slope will the apparent rate constant. As shown in figure 4, straight lines are shown, all three reactions were proven to be first order. And the rate constants were calculated from the slope and tabulated in table 1. Assuming the concentration of PC is substantially higher and the concentrations for Li ion and TPFPB were constant, the reaction constant can be calculated from the apparent constant $k$ ', which can be determined by the slope. The results are tabulated in table 1 . It is clearly demonstrated from the reaction constant $k$, the rate for the $\mathrm{O}_{2}{ }^{--}$disproportionation catalyzed by TPFPB was about 20x and 30x faster than its reactions with $\mathrm{PC}$ and $\mathrm{LiBF}_{4}$, respectively.

Table 1: reaction rate constants calculated from table 3. Initial concentration for $\mathrm{O}_{2}{ }^{--}$was $0.01 \mathrm{M}$.

\begin{tabular}{llllll}
\hline & Concentration (M) & STD & $\mathbf{R}$ & $\boldsymbol{k}^{\mathbf{1}}\left(\mathbf{s}^{\mathbf{- 1}}\right)$ & $\left.\boldsymbol{k}^{-\mathbf{1}} \mathbf{M}^{\mathbf{1}}\right)$ \\
\hline $\boldsymbol{P C}$ & 0.08 & $6.87 \times 10^{-5}$ & 0.998 & 0.003 & 0.037 \\
Li ion & 0.2 & $3.78 \times 10^{-4}$ & 0.960 & 0.004 & 0.02 \\
$\mathbf{T P F P B}$ & 0.009 & $1.59 \times 10^{-4}$ & 0.997 & 0.006 & 0.67 \\
\hline
\end{tabular}

STD stands for standard deviation and $\mathrm{R}$ is the $\mathrm{R}$-value for linear regression, $\mathrm{R}=1$ represents ideal linear.

figure 3

\section{Conclusions}

Lewis acids were found to catalyze the disproportionation of $\mathrm{O}_{2}{ }^{-}$ions in aprotic solution. The catalytic effect is related to the strength of the Lewis acidity, which is the evident that strong Lewis acid TPFPB catalyse much faster disproportionation reaction than week one like Li ion. Strong Lewis acids like tris(pentafluorophenyl)borane can also catalyse the disproportionation of $\mathrm{O}_{2}{ }^{--}$much faster than it can react with a carbonate solvent like PC. Therefore, the negative impacts of the chemical interaction between $\mathrm{O}_{2}{ }^{--}$and carbonate solvents can be minimized in Liair batteries. 


\section{Acknowledgements}

The authors from UMB are indebted to the Assistant Secretary for Energy Efficiency and Renewable Energy, Office of Vehicle Technologies, under the program of Vehicle Technology Program, under Contract Number DEAC02-98CH10886.

\section{Captions}

Figure 1 Calibration curve of DPPH

Figure 2. ESR spectra of $0.01 \mathrm{M} \mathrm{O}_{2}{ }^{--}$in DMSO taken at different times after adding $0.2 \mathrm{M}$ $\mathrm{LiBF}_{4}$.

Figure 3 The change of the natural logarithm of $\mathrm{O}_{2}{ }^{--}$concentration with time.

\section{Reference}

1. D.T. Sawyer, Inorganic Chem. 16(1977)499-501.

2. M.E. Peover, B.S. White, Electrochim. Acta 11(1966)1061-1067.

3. Q. Wang, X.Q. Yang, D.Y. Qu, Carbon 61(2013)336-341.

4. F. Mizuno, S. Nakanishi, Y. Kotani, S. Yokoishi, H. Iba, Electrochemistry 2010, 78, 403405.

5. Y. Chen, S.A. Freunberger, Z. Peng, F. Barde, P.G. Bruce, J. Am. Chem. Soc. 2012, 134, 7952-7957. 
6. K.U. Schwenke, S. Meini, X.H. Wu, H.A, Gasteiger, M. Piana, Phys. Chem. Chem. Phys. 15(2013)11830-11839.

7. V.S. Bryantsev, J. Uddin, V. Giordani, W. Walker, D. Addison, G.V. Chase, J. Electrochem. Soc. 160(2013)A160-A171.

8. D. Zheng, Q. Wang, H.S. Lee, X.Q. Yang, D.Y.Qu, Chem. Eur. J, 19(2013)8679-8683.

9. H.S. Lee, X.Q. Yang, C.L. Xiang, J. McBreen, L.S. Choi, J. Electrochem. Soc. 1998, 145, 2813-2818.

10. N. D. Yordanov, Appl. Magn. Reson., 10(1996)339-350.

11. N. D. Yordanov, Kalina Ranguelova, Spectrochimica Acta Part A, 56(2000)373-378.

12. D. Cordischi, M Occhiuzzi, R. Dragone, Appl. Magn Reson. 16(1999)427-445.

13. Milan Mazur, Jan Moncol, Marian Valko, Harry Morris, Analytica Chimica Acta, (538)2005165-174.

14. V. Yu. Nagy, Analytica Chimica Acta, 339(1997)1-11.

15. D.T. Sawyer, J.S. Valentine, Acc. Chem. Res. 14(1981)393-400 


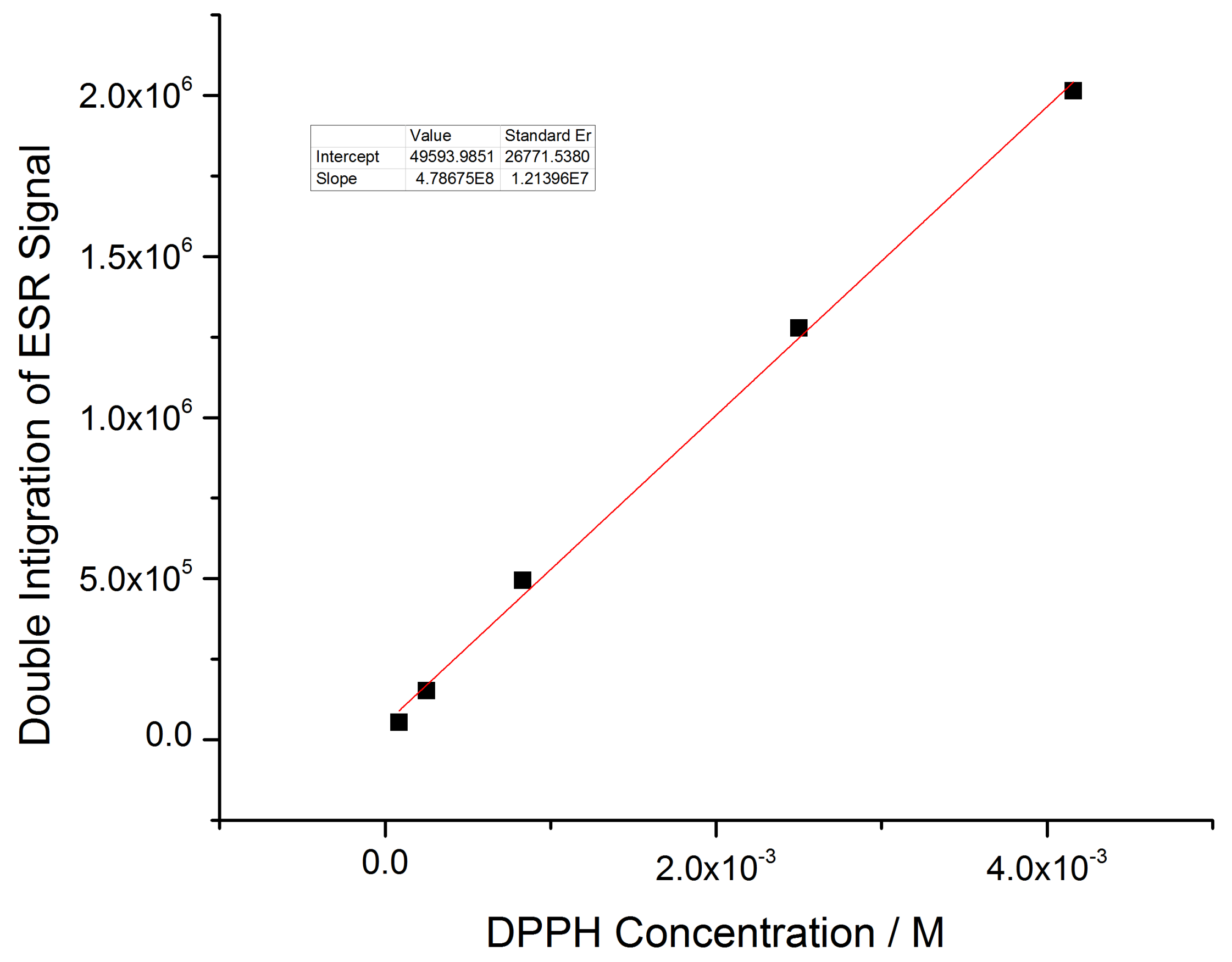




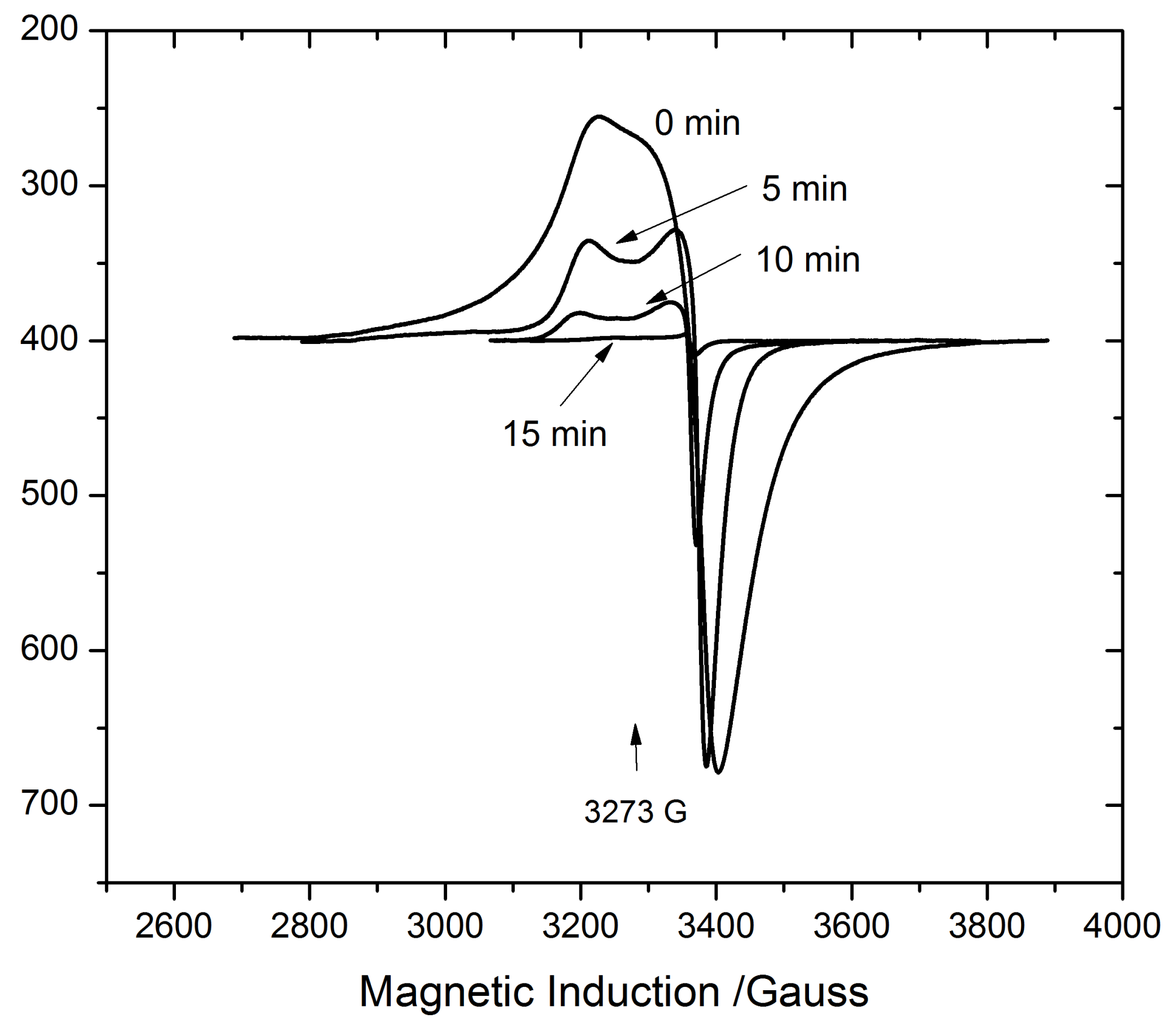




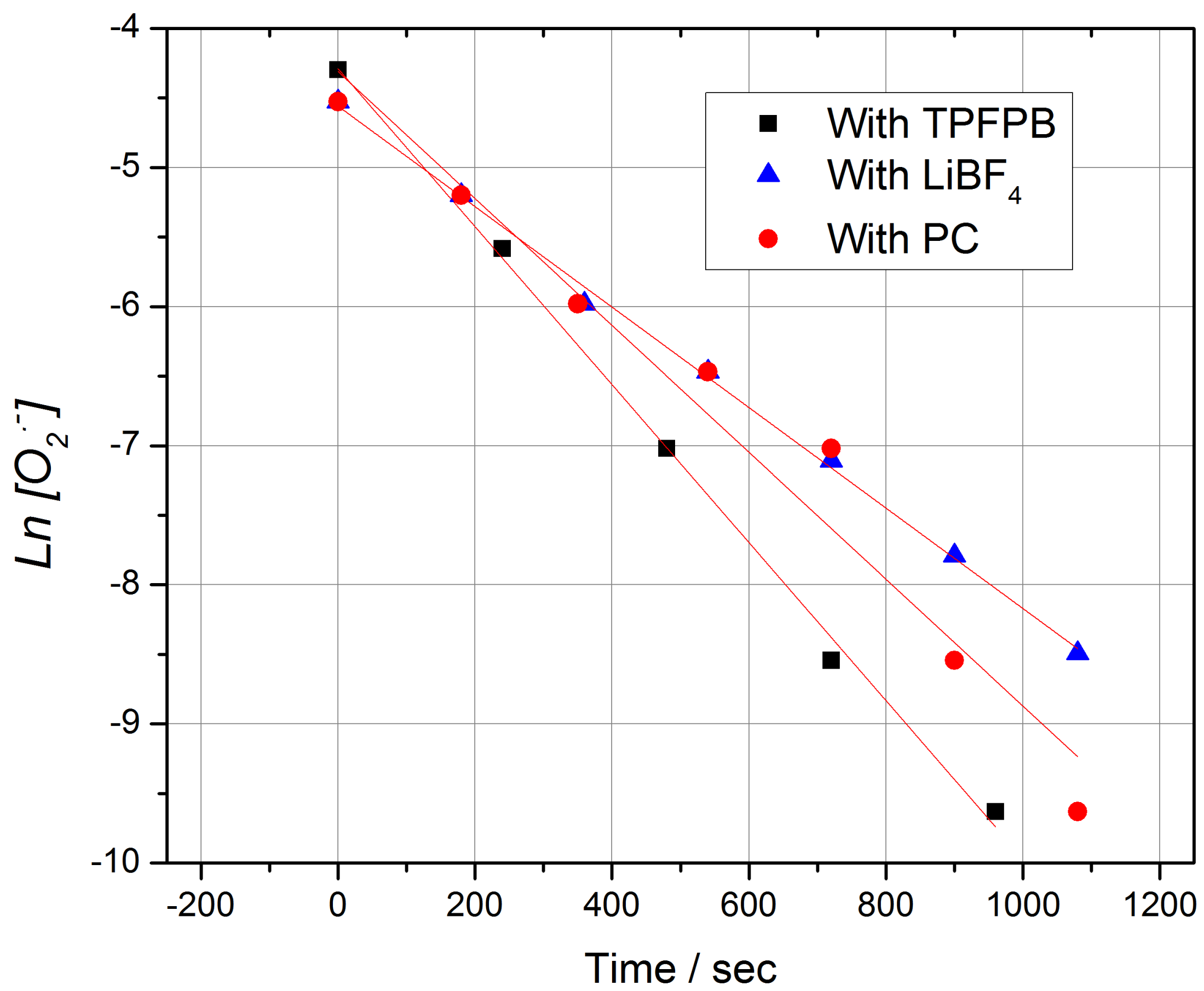

